\title{
Current role of the chimney technique in the treatment of complex abdominal aortic pathologies: A position paper from the PERICLES Registry investigators
}

\author{
Konstantinos P Donas', Frank Criado², Giovanni Torsello ${ }^{3}$, \\ Vicente Riambau ${ }^{4}$, Salvatore Scali ${ }^{5}$, David Minion ${ }^{6}$, \\ Jason T. Lee ${ }^{7}$, Mario Lachat ${ }^{8}$, Edward $Y$ Woo $^{9}$, and \\ Frank J Veith ${ }^{7,10}$; \\ on behalf of the PERICLES Registry Investigators (Fazzini S, \\ Taneva GT, Dalman RL, Tran K, Pecoraro F, Bisdas T, Seifert S, \\ Esche M, Gasparini D, Frigatti P, Adovasio R, Mucelli FP, \\ Damrauer SM, Salenius J, Suominen V, Mangialardi N, Ronchey \\ S, Mestres G, Mosquera NJ)
}

\section{Keywords}

Chimney technique, pararenal aneurysms, endovascular aortic repair

\section{Introduction}

Historically, chimney/snorkel endovascular aortic repair (Ch-EVAR) emerged as a rescue technique to revascularize and/or preserve inadvertently covered critical branch vessels during infrarenal aortic endografting. ${ }^{1,2}$ Next, in its evolutionary path, Ch-EVAR offered a viable treatment option for complex aortic repair, and particularly in situations where fenestrated/branched EVAR was not a therapeutic option due to the lack of availability and/or anatomical constraints. ${ }^{3}$ In this context, this technique offered distinct advantages such as off-the-shelf availability, straightforward implantation techniques, and lower resource use-intensity enabling performance by a large number of operators managing patients in many centers around the world.

\section{Summary of the published evidence on Chimney EVAR from the PERICLES registry data (Table I)}

After the initial description of Ch-EVAR as a bailout technique for unintended renal artery coverage, the proliferation and subsequent adoption by operators increasingly occurred over several years. ${ }^{4}$ However, a significant limitation to the expanded use of this technique was the lack of a strong scientific-evidence foundation. Notably, this all changed in 2015 with the landmark publication of the clinical results from the PERformance of the chImney technique for the treatment of Complex aortic pathoLogiES (PERICLES) registry demonstrating promising outcomes in a variety of complex aneurysm patients,

\footnotetext{
'Department of Vascular Surgery and Research Vascular Centre, Asclepios Clinic Langen, University of Frankfurt, Germany ${ }^{2}$ MedStar Union Memorial Hospital, Baltimore, MD, USA

${ }^{3}$ Department of Vascular Surgery, St. Franziskus Hospital Münster, Münster, Germany

${ }^{4}$ Vascular Surgery Division, Hospital Clínic, University of Barcelona, Barcelona, Spain

${ }^{5}$ Division of Vascular Surgery and Endovascular Therapy, University of Florida, Gainesville, FL, USA

${ }^{6}$ Department of Vascular Surgery, University of Kentucky, Lexington, KY, USA

${ }^{7}$ Division of Vascular Surgery, Stanford University Medical Center, Stanford, CA, USA

${ }^{8}$ Aortic Center Hirslanden, Zurich, Switzerland

${ }^{9}$ MedStar Washington Hospital Center, Washington, DC, USA

${ }^{10}$ Division of Vascular Surgery, New York University Medical Center, New York, NY, USA
}

\section{Corresponding author:}

Konstantinos P Donas, Department of Vascular Surgery and Research Vascular Centre, Asclepios Clinic Langen, University of Frankfurt, Röntgenstrasse 20, 63225 Langen, Germany.

Email: konstantinos.donas@gmail.com 
including symptomatic and ruptured pathologies, at high- and low-volume medical centers throughout Europe and the USA. ${ }^{5}$

The mean preoperative maximum diameter of the aneurysm sac was more than $70 \mathrm{~mm}$ highlighting the need for expedited treatment. The registry involved 13 international centers with a total of 517 patients who had 898 implanted chimney grafts. ${ }^{5}$ The reported technical success was $97.1 \%$, with a 30 -day mortality of $4.9 \%$ and estimated primary patency of $94.1 \%$ at a mean follow-up of 17.1 months. ${ }^{5}$ Importantly, there were no late aneurysm ruptures.

\section{Device configurations/combinations}

Since the procedure involves the use of off-the-shelf devices in an off-label manner, Ch-EVAR practitioners have used several different main-body EVAR devices, as well as covered, uncovered and balloon-expandable or self-expanding nitinol stents. Such a plethora of available options led to the frequent use of heterogeneous combinations which can potentially influence the outcomes. In this context, Scali et al. evaluated various device combinations finding that main-body devices with nitinol stent structure and polyester fabric (e.g. Medtronic Endurant, Santa Rosa, USA) in combination with balloon-expandable covered chimney stents had the highest survival at three years $(93 \%){ }^{6}$

\section{Impact of the degree of aortic stent-graft oversizing}

Donas et al. found that less than $20 \%$ stent graft oversizing was associated with higher risk of type IA endoleak when compared with $30 \%$ oversizing $(14.3 \%$ vs. $2.1 \%, p=.02){ }^{7}$ Therefore, $30 \%$ main aortic graft oversizing was recommended to optimize proximal sealing, regardless of the number of deployed chimney grafts.

\section{Risk of stroke}

A noteworthy criticism of Ch-EVAR for treatment of juxatrenal aneurysms (compared with fenestrated graft strategies) is the risk of stroke related to the need to use upper extremity access. A stroke rate of $0-4.0 \%$ has been reported by various centers performing ChEVAR. To address this concern, in a novel analysis of the PERICLES registry, Bosiers et al. reported a clinically relevant cerebrovascular event rate of $1.9 \%{ }^{8}$ Not surprisingly, the use of bilateral upper extremity access was found to be an independent predictor factor associated with a 2.8-fold increased risk for postoperative stroke. ${ }^{8}$ This important finding led to the recommendation of using a single-arm access point (e.g. left upper extremity) for Ch-EVAR procedures.

\section{Gender-related outcomes}

Another significant contribution from the PERICLES registry was the information gained about sex differences in outcome after complex endovascular aortic repair. Historically, female gender has been reported to be a risk factor for worse postoperative outcomes after both complex endovascular and open aortic repair. Torsello et al. presented a robust gender-stratified analysis for Ch-EVAR patients in the PERICLES registry and found no significant difference in outcomes between men and women with respect to terms of freedom from iliac access reintervention $(p=.44)$, freedom from chimney stent occlusion $(p=.228)$, or mortality $(p=.59) .{ }^{9}$ These results further underline the utility of the Ch-EVAR technique due to its versatility to use low profile, flexible abdominal aortic devices in female patients who may harbor hostile iliac access vessels and/or more challenging proximal aortic neck landing zone morphologies.

\section{Use of chimney grafts in type IA endoleaks after EVAR}

Indeed, the lessons learned from the PERICLES registry make a compelling illustration about the flexibility of Ch-EVAR especially given its ability for use in both elective and non-elective settings. Furthermore, iterative analyses from the registry brought into sharper focusing on other noteworthy applications of ChEVAR such as the remediation of type 1A endoleak after standard infrarenal EVAR. ${ }^{10}$ Ronchey et al. evaluated 39 patients from the PERICLES registry who were treated for type IA endoleaks that occurred after a previous infrarenal EVAR. ${ }^{10}$ They noted a technical success rate of $89.7 \%$, with a $7.6 \%$ risk of persistent type IA endoleak at 30 days and a primary chimney stent patency of $94.3 \%$ at 36 months. Thirty-day operative mortality was $2.6 \%$, with a $7.7 \%$ all-cause mortality at a mean follow-up of nearly two years. ${ }^{10}$ These results suggest that Ch-EVAR could be considered a good treatment option (when compared with open surgical conversion) for this difficult group of patients.

\section{Classification and etiological factors for persistent gutter-related type IA endoleaks}

The presumed Achilles heel of Ch-EVAR is the concern regarding gutter endoleaks between the chimney stent and aortic main body stent graft. However, a critically important and often overlooked observation is that the majority of Ch-EVAR gutter endoleaks detected on 
completion intraoperative angiography can be expected to resolve spontaneously by the time the first postoperative CTA is performed. This is an important distinction since it is not unusual for presentations, discussions and published editorials to site that $\mathrm{Ch}$ EVAR gutter endoleak rates are exceedingly high. The discussion often aggregates the gutter leaks into a sum total of those detected on completion angiography, the first CTA and even late-onset endoleaks. The PERICLES registry collaborators identified two key factors associated with persistent gutter endoleak. ${ }^{11}$ One was the degree of aortic stent-graft oversizing, and the other was related to insufficient length of the new proximal seal zone. ${ }^{11}$ The newest findings regard the triple and four/fold chimneys use within the PERICLES registry-treated patients. Although the rates of type IA endoleak $(13.4 \%)$, chimney graft occlusion $(12.7 \%)$ and ischemic stroke $(2.9 \%)$ are higher compared to the prevailing single chimney evidence, the use seems safe with promising midterm results regarding patency and mortality. Table 1 provides a summary of the evidence of Ch-EVAR based upon the published data of the PERICLES registry cohort.

Indications for first-line treatment, as well as anatomical constraints to consider indication for chimney

Table I. PERICLES Registry findings from first publication in 2015 to latest in 2019.

\begin{tabular}{|c|c|c|c|}
\hline & Year & Topic & Main findings/conclusion \\
\hline $\begin{array}{l}\text { Donas et al. Annals of } \\
\text { Surgery }\end{array}$ & 2015 & $\begin{array}{l}\text { Overall outcomes in a global } \\
\text { registry of Ch-EVAR patients } \\
\text { (PERICLES) }\end{array}$ & $\begin{array}{l}5 \text { I } 7 \text { patients treated with } 898 \text { chimney grafts }(692 \\
\text { renal arteries, I } 56 \text { SMA, } 50 \text { celiac) with a mean } \\
\text { follow-up of I7.I months. Thirty-day mortality } \\
\text { was } 4.9 \% \text {, and three-year estimated survival of } \\
74.9 \% \text {. Primary patency was } 94.1 \% \text { at latest follow- } \\
\text { up. New sealing zone of approximately } 20 \mathrm{~mm} \text { in } \\
\text { length and oversizing of the aortic stent graft of } \\
30 \% \text { represent key findings. }\end{array}$ \\
\hline $\begin{array}{l}\text { Donas et al. Journal of } \\
\text { Endovascular Therapy }\end{array}$ & 2017 & $\begin{array}{l}\text { Classification of gutter-related } \\
\text { endoleaks }\end{array}$ & $\begin{array}{l}\text { Pattern A: Excessive aortic stent-graft Oversizing } \\
>30 \% \text {, enfolding } \\
\text { Pattern B: Undersized aortic stent-graft oversizing } \\
\quad<30 \% \\
\text { Pattern C: Inadequate seal zone }\end{array}$ \\
\hline $\begin{array}{l}\text { Scali et al. Journal of } \\
\text { Vascular Surgery }\end{array}$ & 2018 & $\begin{array}{l}\text { Identifying optimal device com- } \\
\text { binations for Ch-EVAR }\end{array}$ & $\begin{array}{l}\text { Use of a nitinol/polyester main-body endograft in } \\
\text { combination with balloon-expandable covered } \\
\text { chimney stents portended greater all-cause sur- } \\
\text { vival after Ch-EVAR. Presence of multiple chimney } \\
\text { grafts has a I.8-fold higher risk of stent occlusion. }\end{array}$ \\
\hline $\begin{array}{l}\text { Bosiers et al. Journal of } \\
\text { Vascular Surgery }\end{array}$ & 2018 & $\begin{array}{l}\text { Prognostic factors of major } \\
\text { stroke after Ch-EVAR }\end{array}$ & $\begin{array}{l}\text { Ch-EVAR associated with a } 1.9 \% \text { risk of post-oper- } \\
\text { ative transient ischemic attack or stroke. Bilateral } \\
\text { upper extremity access (OR 2.79), ruptured set- } \\
\text { tings (OR 5.33) and longer operative times were } \\
\text { associated with increased risk of post-operative } \\
\text { stroke after Ch-EVAR. }\end{array}$ \\
\hline Torsello et al. Vascular & 2018 & $\begin{array}{l}\text { Gender-related differences in } \\
\text { Ch-EVAR outcome }\end{array}$ & $\begin{array}{l}\text { At a mean follow-up of } 36 \text { months, there was no } \\
\text { statistically significant difference in freedom from } \\
\text { patency loss }(84 \% \text { vs. } 80 \% \text {, female vs. male, } p=.33 \text {, } \\
\text { reintervention }(p=.44) \text {, or } 30 \text {-day mortality }(0 \% \\
\text { vs. } 1.4 \%, p=.59) \text { with respect to gender. }\end{array}$ \\
\hline $\begin{array}{l}\text { Ronchey et al. Journal of } \\
\text { Endovascular Therapy }\end{array}$ & 2018 & $\begin{array}{l}\text { Evaluation of Ch-EVAR to treat } \\
\text { type IA endoleaks after stan- } \\
\text { dard EVAR. }\end{array}$ & $\begin{array}{l}\text { Technical success was achieved in } 35 \text { of } 39 \text { cases } \\
(89.7 \%) \text {, with a } 7.6 \% \text { risk of persistent type IA } \\
\text { endoleak at } 30 \text { days. Thirty-day mortality was } \\
2.6 \% \text {, with a } 94.3 \% \text { primary patency at } 36 \text { months. }\end{array}$ \\
\hline Donas et al. Vascular & 2019 & $\begin{array}{l}\text { Impact of device oversizing on } \\
\text { outcomes after Ch-EVAR }\end{array}$ & $\begin{array}{l}\text { Oversizing of } 30 \% \text { with the Endurant stent graft was } \\
\text { associated with significantly lower risk of type IA } \\
\text { endoleaks requiring intervention. }\end{array}$ \\
\hline $\begin{array}{l}\text { Taneva et al. Journal of } \\
\text { Vascular Surgery }\end{array}$ & 2019 & $\begin{array}{l}\text { Evaluation of Ch-EVAR in supra- } \\
\text { renal aortic pathologies }\end{array}$ & $\begin{array}{l}\text { Safe use of triple Ch-EVAR involving the superior } \\
\text { mesenteric artery but higher incidence of type IA } \\
\text { gutter-related endoleaks compared to single/ } \\
\text { double chimney cases }\end{array}$ \\
\hline
\end{tabular}


Table 2. Indications supporting primary use.

Clinical:
- Symptomatic/contained ruptured JAAA
Symptomatic/ruptured juxtarenal pathologies such
as penetrating ulceration
Type 1 A endoleak after EVAR
Provider/Center:
- No availability of fenestrated endografts
- No preference and/or center expertise in use of
fenestrated endografts due to either high costs or
limited experience
Less costs
Anatomical:
Aneurysm involvement of only one renal artery and
distance to the more proximal uninvolved renal
artery is $>15 m m$
Involvement of 2 renal arteries with orifice at the
same level and distance to the SMA is $>15 \mathrm{~mm}$

Table 3. Considerations limiting primary use.

New sealing neck:
- $\quad$ Distance between lowest renal artery and SMA $<15 \mathrm{~mm}$
- $\quad$ Severe circumferential calcification
- Narrow $(<25 \mathrm{~mm})$ or wide $(>30 \mathrm{~mm})$ neck diameter
- Infra/suprarenal/supra SMA angulation $>75^{\circ}$
Renal artery:
- Diameter $<5 \mathrm{~mm}$
- $\quad$ Cranial orientation of vessel
- $\quad$ Calcified high-grade stenosis
- Early bifurcation of the renal artery
- Multiple and/or indispensible accessory renal arteries
Proximal Access:
- Shaggy thoracic aorta and/or significant atherosclerotic
plaque in the left subclavian artery
- Bliac Access:
- Bilateral occlusion
Bilateral diameter $<5$ mm

EVAR technique are outlined in Tables 2 and 3, respectively. ${ }^{12}$

\section{New evidence and future directions}

For the first time, Ch-EVAR has been included in the latest 2019 AAA Treatment Guidelines from the
European Society for Vascular Surgery (ESVS) where the technique is recommended in urgent cases and when fenestrated repair is not feasible and/or contraindicated. ${ }^{13}$ The adoption of Ch-EVAR into the ESVS AAA guidelines is an important example that illustrates the significant and increasing role of this technique in the management of complex aortic pathologies. Notably, the recently published guidelines assign the same level of evidence (C) to both Ch-EVAR and fenestrated/branched EVAR.$^{13}$ Moreover, the CE mark chEVAR approval in case of the Endurant abdominal stent graft with a balloon expandable covered stent as chimney in having renal indication in 2016 allowed the use of a homogeneous combination of devices optimizing the results. This fact has changed the clinical practice standardizing the technique and providing a more therapeutic profile than a bail out solution. In this context, the on-going multicenter prospective Ch-EVAR trial (ENCHANT: Clinical Trialsgov. Identifier: NCT03320252) might well warrant a designation that features a higher level of evidence (e.g. B) once the trial is completed and patient outcomes are analyzed. ${ }^{14}$ Notwithstanding the evolution in evidence supporting the use of Ch-EVAR, there is little doubt that the controversy surrounding ChEVAR will continue for the foreseeable future. However, we feel confident that the existing and upcoming PERICLES registry results together with the dissemination of the ENCHANT study results will go a long way to propel Ch-EVAR in its evolution as a viable treatment option within the armamentarium of surgeons managing complex aneurysms. Ultimately, this will result in an improved perception of its utility and efficacy within the vascular community.

\section{Declaration of conflicting interests}

The author(s) declared no potential conflicts of interest with respect to the research, authorship, and/or publication of this article.

\section{Funding}

The author(s) received no financial support for the research, authorship, and/or publication of this article.

\section{ORCID iD}

Gergana T Taneva (D) https://orcid.org/0000-0001-8003-8137

\section{References}

1. Moulakakis KG, Mylonas SN, Avgerinos E, et al. The chimney graft technique for preserving visceral vessels during endovascular treatment of aortic pathologies. J Vasc Surg 2012; 55: 1497-1503. 
2. Lee JT, Greenberg JI and Dalman RL. Early experience with the snorkel technique for juxtarenal aneurysms. J Vasc Surg 2012; 55: 935-946.

3. Lee JT, Lee GK, Chandra V, et al. Comparison of fenestrated endografts and the snorkel/chimney technique. J Vasc Surg 2014; 60: 849-857.

4. Donas KP, Telve D, Torsello G, et al. Use of parallel grafts to save failed prior endovascular aortic aneurysm repair and type Ia endoleaks. J Vasc Surg 2015; 62: 578-584. Doi: 10.1016/j.jvs.2015.04.395.

5. Donas KP, Lee JT, Lachat M, et al. Collected world experience about the performance of the snorkel/chimney endovascular technique in the treatment of complex aortic pathologies: the PERICLES registry. Ann Surg 2015; 262: 546-552.

6. Scali ST, Beck AW, Torsello G, et al. Identification of optimal device combinations for the chimney endovascular aneurysm repair technique within the PERICLES registry. J Vasc Surg 2018; 68: 24-35.

7. Donas KP, Criado FJ, Torsello G, et al. Classification of chimney EVAR-related endoleaks: insights from the PERICLES registry. J Endovasc Ther 2017; 24: 72-74.

8. Bosiers MJ, Tran K, Lee JT, et al. Incidence and prognostic factors related to major adverse cerebrovascular events in patients with complex aortic diseases treated by the chimney technique. J Vasc Surg 2018; 67: 1372-1379.
9. Torsello G, Usai MV, Scali S, et al. Gender-related outcomes of chimney EVAR within the PERICLES registry. Vascular 2018; 26: 641-646.

10. Ronchey S, Fazzini S, Scali S, et al. Collected transatlantic experience from the PERICLES registry: use of chimney grafts to treat post-EVAR type Ia endoleaks shows good midterm results. J Endovasc Ther 2018; 25: 492-498.

11. Donas KP, Usai MV, Taneva GT, et al. Impact of aortic stent-graft oversizing on outcomes of the chimney endovascular technique based on a new analysis of the PERICLES Registry. Vascular 2019; 27: 175-180.

12. Taneva GT, Donas KP, Pitoulias GA, et al. Cost-effectiveness analysis of chimney/snorkel versus fenestrated endovascular repair for high-risk patients with complex abdominal aortic pathologies. $J$ Cardiovasc Surg (Torino) $2020 \mathrm{Feb} ; 61(1): 18-23$.

13. Wanhainen A, Verzini F, Van Herzeele I, et al. European Society for Vascular Surgery (ESVS) 2019 Clinical Practice Guidelines on the Management of Abdominal Aorto-iliac Artery Aneurysms. Eur J Vasc Endovasc Surg 2019 Jan;57(1):8-93.

14. Donas KP and Taneva GT. Evidence of parallel endografting for complex aortic diseases rising: will the technique overcome perceived shadows and move to the next level in 2019 and beyond? Vascular 2019 Aug;27 (4):378-380. 